ITEJ Juli-2020, Volume 5 Nomor 2 Page 97 - 104

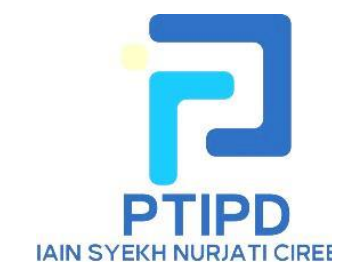

ITEJ
Information Technology Engineering Journals eISSN : 2548-2157

Url : https://syekhnurjati.ac.id/journal/index.php/itej

Email : itej@syekhnurjati.ac.id

\title{
The Use of Learning Media Motion Graphics Towards Students Mathematical Understanding
}

\author{
Ikman Nurhakim Rahadi \\ Fakultas Ilmu Tarbiyah dan \\ Keguruan \\ IAIN Syekh Nurjati Cirebon \\ ikman@syekhnurjati.ac.id
}

\author{
Darwan \\ Fakultas Ilmu Tarbiyah dan \\ Keguruan \\ IAIN Syekh Nurjati Cirebon \\ darwan@syekhnurjati.ac.id
}

\author{
Hendri Handoko \\ Fakultas Ilmu Tarbiyah dan \\ Keguruan \\ IAIN Syekh Nurjati Cirebon \\ hendrihandoko@syekhnurjati.ac.id
}

\begin{abstract}
Learning about the concept and structure of a mathematical material and looking for relationships between them is real math learning. In many math learning materials, students often struggle to understand the concept of the material. The mathematical skills need to be stimulus and encouraged when learning. To practice such skills need innovations such as using motion graphics learning media. The purpose of this research is to know the student's response to the use of motion graphic media, to find out how much the mathematical skills of students after using motion graphic learning media, to know how much influence The media use of motion graphic learning to the students mathematical skills, to determine the effectiveness of the use of motion graphic learning media to the students mathematical skills. This method of research is experimental research with data collection techniques using poll and observation for variable $X$ and test for variable $Y$. Population for this research is all students of grade IX SMP IT Umar Al Khattab Gunung Jati Kabupaten Cirebon, while the sample Taken by the cluster method of random sampling with the elected class IX B SMP IT Umar Al Khattab Gunung Jati Kabupaten Cirebon. Based on the results of the data processing, the student response questionnaire was obtained against the use of media in motion graphic media learning with an average of $85.23 \%$ with very strong criteria. Based on the hypothesis test result obtained $t_{\text {count }}>t_{\text {table }}=9,895>2.063$, then HO rejected or Ha is acceptable, the use of Motion graphics Learning Media is effective against the mathematical understanding of grade IX students SMP IT Umar Al Khattab. It is also supported through an N-Gain value of 65.40 as well as an indicator of the learning effectiveness of a KKM pass of $91.66 \%$ classifying, student response $85.23 \%$, student activity of $77,33 \%$, as well as the ability of the teacher to manage the class that got the value 3.34 .
\end{abstract}

Keywords: learning media, mathematical skills, motion graphic

\section{Pendahuluan}

Pendidikan pada umumnya adalah sarana yang paling strategis untuk menanamkan nilai-nilai, ajaran, keterampilan, pengalaman dan sebagainya yang ke dalam diri peserta didik [1]. Pendidikan dipandang sebagai proses pengembangan manusia agar memperoleh kemampuan sosial dan perkembangan individu yang optimal dan memiliki relasi yang kuat antara individu dengan masyarakat ataupun individu dengan lingkungan budaya sekitarnya[2]. Menurut Undang-undang RI nomor 20 Tahun 2003 tentang Sisdiknas pasal 37 menegaskan bahwa pelajaran matematika merupakan salah satu mata pelajaran wajib bagi siswa pada jenjang pendidikan dasar dan menengah[3]. Dalam era globalisasi dimana dunia sudah tidak memiliki batas baik itu hubungan maupun persaingan, peranan matematika dan 
pendidikan matematika menjadi sangat penting[4]. Ilmu ini bermanfaat melatih penalaran, melatih komunikasi, melatih untuk berfikir logis, serta melatih siswa berfikir teratur, struktur dan konsepsi yang jelas. Matematika dipandang sebagai ilmu yang hanya perihal berhitung dan mengerjakan soal, akan tetapi sebenarnya matematika juga mengajarkan aspek seperti kecermatan, ketelitian, berpikir logis, bertanggung jawab, disiplin, hingga keimanan[5]. Peran matematika adalah sebagai induk ilmu pengetahuan, alat bantu, serta sebagai pembentuk pola pikir[6]. Sementara masalah yang muncul pada pembelajaran matematika khususnya pada materi Dimensi Tiga diantaranya, (1)Dalam dimensi dua siswa masih kesulitan memahami gambar dan dimensi tiga karena belum terbiasa berpikir abstraksi lebih tinggi; (2)kemampuan pemahaman terkait materi prasyarat sebelumnya seperti segitiga dan trigonometri sangat dibutuhkan, saat ini siswa mengalami kesulitan untuk menemukan hubungan matematika yang dipelajari; (3)Metode ceramah masih digemari oleh guru dalam menggunakan metode pembelajaran; (4)Adanya keterbatasan pemakaian media dan beberapa sumber belajar lainnya, baik dari sisi kuantitas maupun kualitas[7]. Pada prosesnya, pembelajaran matematika sering mengalami hambatan untuk mencapai tujuannya. Salah satu yang paling sering terjadi adalah masalah ketika siswa tidak dapat memahami konsep yang sedang diajarkan guru. Siswa sering mengalami blank ketika harus membayangkan atau mamasukkan konsep matematika yang sedang diajarkan oleh guru, hingga siswa mengambil jalan pintas dengan hanya menghafalkan rumus atau materi yang sedang diajarkan tanpa paham konsep materi tersebut. Hal ini juga karena kita terlalu fokus pada pencapaian siswa berupa nilai atau peringkat di sekolah. Oleh karena itu perlu ada perubahan dalam proses pembelajaran matematika sehingga pembelajaran matematika kembali pada hakikatnya namun tetap menyenangkan. Ada banyak hal yang dapat dilakukan pendidik untuk membuat pembelajaran matematika menjadi lebih menarik, diantaranya yaitu dengan menciptakan suasana belajar yang menarik melalui strategi pembelajaran yang kekinian, maupun dengan menggunakan media pembelajaran. Media pembelajaran dapat mengilustrasikan konsep materi dalam pembelajaran melalui hal-hal realita atau semi abstrak agar dapat menstimulus kemampuan berpikir siswa untuk menangkap konsep dalam materi pembelajaran. Media ini juga dapat dikreasikan sehingga tetap menarik siswa agar pembelajaran tetap menyenangkan.

Media Motion Graphic merupakan video ilustrasi beranimasi yang dapat menggambarkan suatu proses, langkah, atau memberikan ilustrasi lain sehingga para siswa mampu menstimulus pikirannya untuk menangkap konsep-konsep yang ada. Motion Graphic adalah grafik yang menggunakan footage dari video atau teknologi animasi untuk menciptakan ilusi dari motion atau gerakan dan biasanya di kombinasikan dengan audio untuk digunakan dalam projek multimedia[8]. Seni dari Motion Graphic adalah kedinamisan dari nama yang di berikan. memberikan kehidupan kepada gambar dan tulisan dan merekam mereka menjadi sebuah pesan yang ingin di sampaikan kepada penontonnya. Penggunaan Motion Graphic ini telah mencakup berbagai bidang termasuk dalam dunia Pendidikan. Motion Graphic digunakan sebagai media pembelajaran yang menarik bagi peserta didik. Media ini dapat berupa ilustrasi yang mampu menggambarkan sebuah konsep yang masih abstrak dengan jelas dan menarik.

\section{A. Analisis Angket}

\section{Metode}

Penggunaan angket berupa pernyataan yang menunjukkan respon baik positif maupun negatif dengan skala Likert. Data yang diperoleh dari hasil angket yang disebarkan kepada siswa diolah dengan rumus berikut:

$$
\text { Prosentase skor angket }=\frac{\text { skor angket }}{\text { skor } \text { maksimum }} \times 100 \%
$$

Pada Tabel 1 merupakan sebuah pedoman untuk memberi interpretasi skor angket yang telah dihitung sebelumnya.

Tabel 1

Interpretasi Skor Angket

\begin{tabular}{|cc|}
\hline Precentage & Interpretasi \\
$0 \%-20 \%$ & Sangat lemah \\
$21 \%-40 \%$ & Lemah \\
$41 \%-60 \%$ & Cukup \\
$61 \%-80 \%$ & Kuat \\
$81 \%-00 \%$ & Sangat kuat \\
\hline
\end{tabular}




\section{B. Uji N-Gain}

Uji N-Gain dipergunakan untuk memperoleh nilai gain yang netral, hal ini untuk menghilangkan anggapan bahwa nilai gain yang terbesar menunjukkan keterampilan proses sains yang paling baik. Adapun Meltzer merumuskan indeks N-Gainyang dipergunakan adalah sebagai berikut[9]:

$$
\text { Indeks N-Gain }=\frac{\text { Postest }- \text { Pretest }}{\text { Skor } \text { max }- \text { Pretest }}
$$

Setelah dihitung nilai gain dari hasil penelitian. Selanjutnya nilai gain diinterpretasikan dengan pedoman yang ada pada Tabel 2 .

Tabel 2

Interpretasi Nilai Gain

\begin{tabular}{|cc|}
\hline Interval Koefisien & Kriteria Gain \\
\hline Gain $\geq 0,07$ & Tinggi \\
$0,7>$ Gain $\geq 0,3$ & Sedang \\
Gain $<0,3$ & Rendah \\
\hline
\end{tabular}

\section{Analisis Ketuntasan Belajar}

Kategorisasi Ketuntasan belajar adalah jika siswa mencapai nilai 70 atau lebih. sementara ketuntasan belajar secara klasikal tercapai apabila siswa yang mencapai nilai minimal 70 lebih dari $85 \%$. Adapun rumus untuk menentukan ketuntasan secara klasikal adalah sebagai berikut:

$$
P=\frac{f}{N} \times 100
$$

\section{Analisis Observasi}

peneliti menggunakan dua lembar observasi yang memiliki tujuan untuk mengetahui aktivitas siswa dan juga kemampuan guru dalam mengelola pembelajaran. Adapun uraian untuk menganalisis hasil observasi tersebut adalah sebagai berikut:

\section{1) Observasi Aktivitas Belajar Siswa}

Analisis ini menggunakan penilaian langsung dan juga dihitung berdasarkan rumus yang ditulis oleh sebagai berikut[10]:

$$
P=\frac{\sum A_{i}}{\sum A_{n}} \times 100 \%
$$

Interpretasi dari hasil perhitungan aktivitas siswa dijelaskan pada Tabel 3 yang menjadi acuan untuk penelitian ini[11].

Tabel 3

Interpretasi Aktivitas Siswa

\begin{tabular}{|cc|}
\hline Aktivitas Siswa & Kategori \\
$0 \% \leq \mathrm{P}<20 \%$ & Kurang Sekali \\
$20 \% \leq \mathrm{P}<40 \%$ & Kurang \\
$40 \% \leq \mathrm{P}<60 \%$ & Cukup \\
$60 \% \leq \mathrm{P}<80 \%$ & Baik \\
$80 \% \leq \mathrm{P} \leq 100 \%$ & Baik Sekali \\
\hline
\end{tabular}

\section{2) Analisis Kemampuan Guru Mengelola Pembelajaran}

Analisis kemampuan guru juga dilakukan secara langsung pada saat proses pembelajaran. Perhitungan nilai kemampuan guru dilakukan dengan cara berikut:

$$
N=\frac{\sum A_{i}}{\sum \mathrm{n}}
$$

Adapun menurut Ampel (2012) interpretasi nilai kemampuan guru dalam mengelola pembelajaran dijelaskan dengan Tabel 4. 
Tabel 4

Interpretasi Kemampuan Guru Mengelola Kelas

\begin{tabular}{|cc|}
\hline Nilai & Kriteria \\
\hline $0,00 \leq$ nilai $<1,50$ & Kurang Baik \\
$1,50 \leq$ nilai $<2,50$ & Cukup \\
$2,50 \leq$ nilai $<3,50$ & Baik \\
$3,50 \leq$ nilai $\leq 4,00$ & Sangat Baik \\
& \\
\hline
\end{tabular}

\section{Hasil dan Pembahasan}

Data yang diperoleh merupakan data variabel bebas (variabel X). Angket tersebut terdiri dari 5 indikator, yaitu indikator peran media Motion Graphic dalam pembelajaran matematika, ketertarikan siswa dalam pembelajaran, minat siswa terhadap penggunaan media Motion Graphic dalam pembelajaran matematika, efektivitas dan efisiensi, peran guru sebagai fasilitator. Angket ini sebelumnya telah divalidasi oleh validator.

Hasil penyebaran angket respon siswa terhadap penggunaan media Motion Graphic pada kelas eksperimen dideskripsikan melalui Tabel 5.

Tabel 5

Hasil Respon Siswa Terhadap Penggunaan Media Motion Graphic

\begin{tabular}{|c|c|c|c|c|c|}
\hline \multirow[b]{2}{*}{ Indikator } & \multicolumn{2}{|c|}{ Skor } & \multicolumn{3}{|c|}{ Rata-Rata } \\
\hline & Maksimal & Rata-Rata & Persentase & Persentase & Kriteria \\
\hline $\begin{array}{l}\text { Peran Media } \\
\text { Motion Graphic }\end{array}$ & 384 & 334 & $86,98 \%$ & & \\
\hline $\begin{array}{l}\text { Ketertarikan } \\
\text { Siswa dalam } \\
\text { Pembelajaran }\end{array}$ & 480 & 405 & $84,38 \%$ & & \\
\hline $\begin{array}{l}\text { Minat Siswa } \\
\text { terhadap } \\
\text { Penggunaan } \\
\text { Media Motion } \\
\text { Graphic }\end{array}$ & 384 & 322 & $83,85 \%$ & $85,23 \%$ & $\begin{array}{c}\text { Sangat } \\
\text { Kuat }\end{array}$ \\
\hline $\begin{array}{l}\text { Efektivitas dan } \\
\text { Efisiensi }\end{array}$ & 480 & 418 & $87,08 \%$ & & \\
\hline $\begin{array}{l}\text { Peran Guru } \\
\text { sebagai Fasilitator }\end{array}$ & 192 & 161 & $83,85 \%$ & & \\
\hline
\end{tabular}

Dari Tabel 5 menyatakan bahwa nilai rata-rata persentase rata-rata keseluruhan data respon siswa terhadap penggunaan media Motion Graphic sebesar 85,23\%. Nilai tersebut termasuk ke dalam kategori sangat kuat. Pada Gambar1 disajikan diagram batang dari hasil data angket respon siswa terhadap penggunaan media motion graphic. 


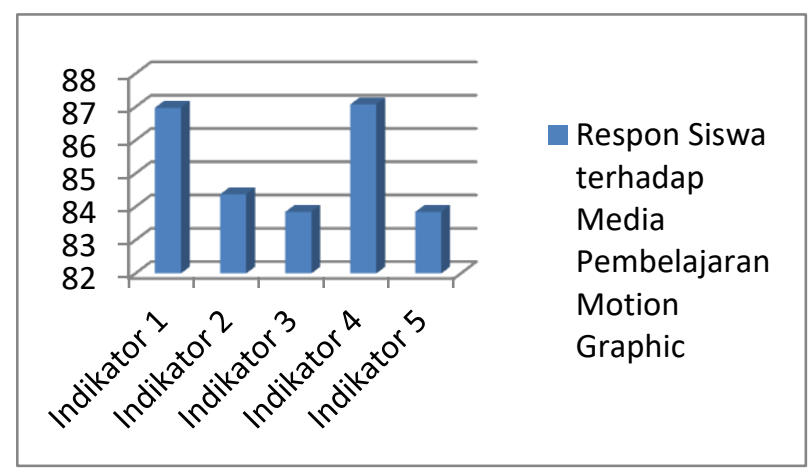

Gambar1 :Diagram Respon Siswa Terhadap Penggunaan Media Pembelajaran Motion Graphic

Selanjutnya Uji Normalized gain atau N-Gain score yang dipergunakan untuk mengetahui efektivitas penggunaan suatu metode atau perlakuan (treatment) tertentu dalam penelitian. Uji $\mathrm{N}$-gain score dilakukan dengan cara menghitung selisih antara nilai posttest dengan nilai pretest. Dalam penelitian one grup pretest posttest design, uji n-gain baru bisa digunakan jika terdapat perbedaan yang signifikan antara rata-rata nilai pretest dan nilai posttest. Hasil rata-rata nilai pretest adalah 58,96 , sedangkan rata-rata nialai posttest yaitu 86,25 . Jadi dapat kita simpulkan bahwa terdapat perbedaan nilai rata-rata pretest dan posttest secara signifikan. Oleh karena itu, kita bisa lanjutkan mencari nilai $\mathrm{N}$-gain score. Adapun perhitungan uji n-gain ditampilkan pada Tabel 6.

Tabel 6

Hasil Uji N-Gain

\begin{tabular}{|cc|c|}
\hline No & Kode Siswa & N-Gain Score \\
\hline 1 & E-1 & 28.57 \\
2 & E-2 & 20 \\
3 & E-3 & 66.67 \\
4 & E-4 & 75 \\
5 & E-5 & 50 \\
6 & E-6 & 87.5 \\
7 & E-7 & 22.22 \\
8 & E-8 & 71.43 \\
9 & E-9 & 71.43 \\
10 & E-10 & 80 \\
11 & E-11 & 45.45 \\
12 & E-12 & 100 \\
13 & E-13 & 100 \\
14 & E-14 & 71.43 \\
15 & E-15 & 60 \\
16 & E-16 & 80 \\
17 & E-17 & 100 \\
18 & E-18 & 72.73 \\
19 & E-19 & 100 \\
20 & E-20 & 33.33 \\
21 & E-21 & 54.55 \\
22 & E-22 & 66.67 \\
23 & E-23 & 100 \\
24 & E-24 & 12.5 \\
Rata-Rata & 65.40 \\
& Minimal & 12.5 \\
Maksimal & 100 \\
\hline
\end{tabular}


Selanjutnya ketuntasan belajar siswa secara klasikal. Presentase yang harus diperoleh untuk dinyatakan tuntas belajar secara klasikal adalah $85 \%$ siswa yang dinyatakan lulus secara individual dari jumlah siswa yang ada dikelas. Perhitungan ini disajikan pada Tabel 7.

Tabel 7

Hasil Ketuntasan Belajar Siswa

\begin{tabular}{|cccc|}
\hline Interval nilai & Kategori & Frekuensi & Precentage \\
\hline $70-100$ & Lulus & 22 & $91,66 \%$ \\
$0-69$ & Belum Lulus & 2 & $8,34 \%$ \\
\hline
\end{tabular}

Tabel 7 menunjukkan bahwa hasil tes sesudah menggunakan media motion graphic terdapat 22 orang siswa $(91,66 \%)$ dinyatakan lulus atau tuntas belajar, sementara terdapat 2 siswa $(8,34 \%)$ dinyatakan belum lulus atau belum tuntas belajar. Berdasarkan hasil tersebut maka secara klasikal dinyatakan sudah tercapainya ketuntasan belajar pada kelas tersebut.

Selanjutnya pengecekan hasil observasi aktivitas siswa dan juga kemampuan guru mengelola kelas. Dalam hal ini pembelajaran dikatakan efektif apabila aktivitas siswa berkriteria baik dengan Precentage minimal 60\% dan juga kemampuan guru mengelola kelas bernilai baik dengan nilai minimal 2,50.

Lembar pertama observasi adalah untuk mengetahui aktivitas siswa dalam pembelajaran. Dalam lembar observasi aktivitas siswa terdapat 5 indikator dan 15 kriteria penilaian.

Indikator tersebut meliputi Kesiapan siswa menerima materi pelajaran, Antusiasme siswa dalam mengikuti kegiatan diskusi kelompok, Aktivitas siswa dalam kegiatan diskusi kelompok, Aktivitas siswa dalam memecahkan masalah, Partisipasi siswa dalam menutup kegiatan pembelajaran. Lembar observasi ini telah divalidasi oleh validator. Hasil perhitungan observasi aktivitas siswa disajikan Tabel 8.

Tabel 8

Hasil Observasi Aktivitas Siswa

\begin{tabular}{|c|c|c|c|}
\hline Indikator & Skor Indikator & $\begin{array}{l}\text { Precentage } \\
\text { Indikator }\end{array}$ & Kategori \\
\hline $\begin{array}{l}\text { Kesiapan siswa menerima materi } \\
\text { pelajaran }\end{array}$ & 13 & $86,67 \%$ & Baik Sekali \\
\hline $\begin{array}{l}\text { Antusiasme siswa dalam mengikuti } \\
\text { kegiatan diskusi kelompok }\end{array}$ & 12 & $80 \%$ & Baik Sekali \\
\hline $\begin{array}{l}\text { Aktivitas siswa dalam kegiatan } \\
\text { diskusi kelompok }\end{array}$ & 12 & $80 \%$ & Baik Sekali \\
\hline $\begin{array}{l}\text { Aktivitas siswa dalam memecahkan } \\
\text { masalah }\end{array}$ & 11 & $73,33 \%$ & Baik \\
\hline $\begin{array}{l}\text { Partisipasi siswa dalam menutup } \\
\text { kegiatan pembelajaran }\end{array}$ & 10 & $66,67 \%$ & Baik \\
\hline Jumlah & & \multicolumn{2}{|c|}{58} \\
\hline Skor Maksimal & & \multicolumn{2}{|c|}{75} \\
\hline Precentage & & \multicolumn{2}{|c|}{$77,33 \%$} \\
\hline Kategori & & \multicolumn{2}{|c|}{ Baik } \\
\hline
\end{tabular}

Dari Tabel 8 didapat bahwa nilai rata-rata persentase keseluruhan data observasi siswa terhadap aktivitas siswa sebesar $77,33 \%$. Nilai tersebut termasuk ke dalam kategori baik. Apabila disajikan dalam diagram batang akan nampak seperti pada

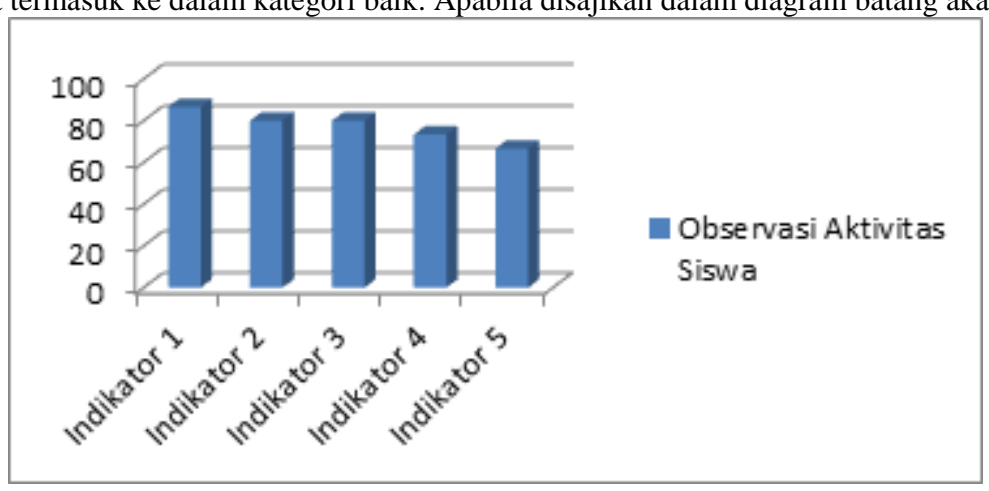

Gambar 2 . 


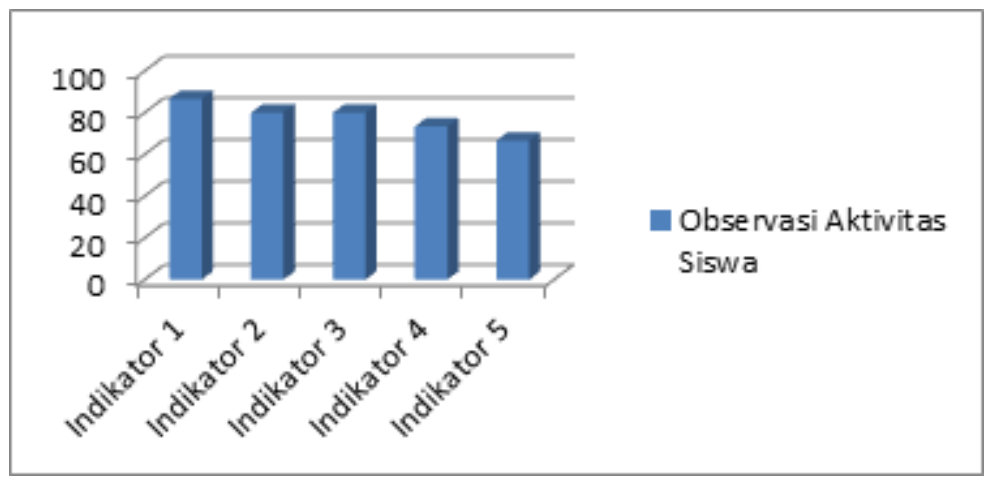

Gambar 2

Diagram Hasil Observasi Aktivitas Siswa

Selanjutnya hasil observasi kemampuan guru mengelola pembelajaran. Lembar kedua observasi mengenai kemampuan guru mengelola pembelajaran terdiri dari 6 indikator penilaian dan 28 kriteria penilaian.

Lembar observasi terdiri dari 6 indikator penilaian, yaitu Membuka dan menutup pembelajaran, Menjelaskan, Strategi yang digunakan, Variasi, Metode, Bertanya. Lembar observasi ini telah divalidasi oleh validator. Pada Tabel 9 disajikan hasil dari perhitungan observasi kemampuan guru mengelola kelas.

Tabel 9

Hasil Observasi Kemampuan Guru Mengelola Pembelajaran

\begin{tabular}{|lccc|}
\multicolumn{1}{c}{ Indikator } & Skor & \multicolumn{2}{c|}{ Skor Keseluruhan } \\
Membuka dan menutup pembelajaran & Nilai Rata-Rata & Kategori & Nilai Rata-Rata \\
Kategori \\
Menjelaskan & 3,42 & Baik & \\
Strategi yang digunakan & 3,33 & Baik & \\
Variasi & 3,5 & Baik Sekali & 3,34 \\
Metode & 3,57 & Baik Sekali & Baik \\
Bertanya & 3,5 & Baik Sekali & \\
\hline
\end{tabular}

Dari Error! Reference source not found. didapat bahwa nilai rata-rata keseluruhan data observasi terhadap kemampuan guru mengelola pembelajaran adalah 3,34. Nilai tersebut termasuk ke dalam kategori baik. Sementara pada

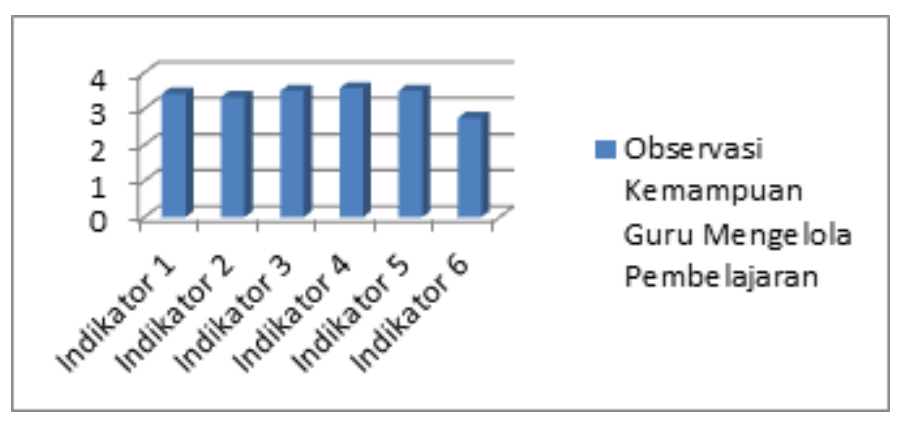

Gambar 3 disajikan hasil perhitungan observasi kemampuan guru mengelola pembelajaran. 


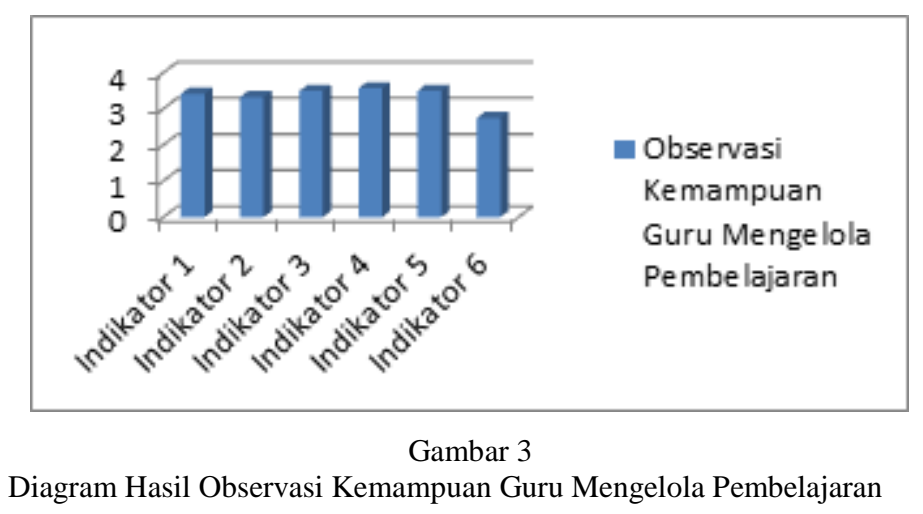

IV. KESIMPULAN

Berdasarkan data-data yang sudah dipaparkan sebelumnya. Dapat disimpulkan bahwa media pembelajaran motion graphic efektif terhadap pemahaman matematis siswa. Hal dikuatkan dengan data hasil perhitungan yang diperoleh berupa nilai N-Gain sebesar 65,40 , respon siswa terhadap media pembelajaran motion graphic mencapai $85,23 \%$, ketuntasan belajar yang mencapai $91,66 \%$, serta kedua hasil observasi yang masing masing mendapat nilai 77,33\% dan nilai 3,34.

\section{REFERENCES}

[1] Anike and H. Handoko, "PEMBELAJARAN MATEMATIKA MODEL JIGSAW MELALUI PENDEKATAN DISCOVERY LEARNING,” EduMa, vol. 7, no. 1, pp. 109-118, 2018.

[2] Z. Idris, Dasar-Dasar Kependidikan. Padang: Angkasa Raya, 1987.

[3] L. H. Jufri, "Penerapan Double Loop Problem Solving Untuk Meningkatkan Kemampuan Literasi Matematis Level 3 Pada Siswa Kelas Viii Smpn 27 Bandung," J. LEMMA, vol. 2, pp. 52-62, 2015.

[4] P. . Suwarno, P. Suparno, and Rahmanto, Pendidikan Sains yang Humanistis. Yogyakarta: Kanisius, 1998.

[5] A. Jibra, "EFEKTIVITAS PENERAPAN MODEL PROBLEM BASED LEARNING DENGAN KOMBINASI PENDEKATAN SAINTIFIK DAN PROBLEM POSING DALAM PEMBELAJARAN MATEMATIKA,” J. Educ. Sci. Technol., vol. 2, pp. 1-9, 2016.

[6] H. Handoko, "Pembentukan Keterampilan Berpikir Kreatif pada Pembelajaran Matematika Model SAVI Berbasis Discovery Strategy Materi Dimensi Tiga Kelas X," J. EduMa, vol. 6, pp. 85-95, 2017.

[7] H. Handoko and Winarno, "Pengembangan Perangkat Pembelajaran Matematika melalui Pendekatan Scaffolding Berbasis Karakter," J. Pendidik. Mat., vol. 8, pp. 411-423, 2019.

[8] A. A. A. Nurmansyah, Muhamad Rendi Ratnamulyani, Ike Kusumadinata, "Hubungan Motion Graphic Sebagai Konten Promosi Sekolah di Media Sosial,” J. Commun., vol. 1, pp. 77-90, 2019.

[9] D. E. Meltzer, "The relationship between mathematics preparation and conceptual learning gains in physics : A possible "“ hidden variable "” in diagnostic pretest scores," Am. J. Phys., vol. 70, pp. 1259-1268, 2002.

[10] Ariffudin, "Efektivitas Penerapan Model Experiental Learning dalam Pembelajaran Matematika Materi Bangun Ruang pada Siswa Kelas VIII SMP Negeri 9 Parepare," J. Pendidik. BUM, vol. 1, pp. 1-15, 2017.

[11] S. Arikunto, Prosedur Penelitian Suatu Pendekatan Praktik. Jakarta: Rineka Cipta, 2006. 